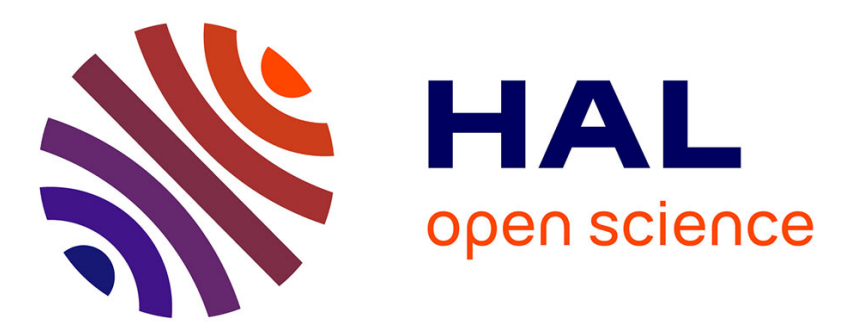

\title{
SBAS Guidelines For Shipborne Receiver Based On Imo Res. A.1046 (27): EGNOS Performance Assessment In Norwegian Coast
}

\author{
Sergio Magdaleno, Elisabet Lacarra, Nuria Blanco, Manuel López
}

\section{To cite this version:}

Sergio Magdaleno, Elisabet Lacarra, Nuria Blanco, Manuel López. SBAS Guidelines For Shipborne Receiver Based On Imo Res. A.1046 (27): EGNOS Performance Assessment In Norwegian Coast. ITSNT 2018, International Technical Symposium on Navigation and Timing, Oct 2018, Toulouse, France. 10.31701/itsnt2018.07 . hal-01942272

\section{HAL Id: hal-01942272 \\ https://hal-enac.archives-ouvertes.fr/hal-01942272}

Submitted on 5 Dec 2018

HAL is a multi-disciplinary open access archive for the deposit and dissemination of scientific research documents, whether they are published or not. The documents may come from teaching and research institutions in France or abroad, or from public or private research centers.
L'archive ouverte pluridisciplinaire HAL, est destinée au dépôt et à la diffusion de documents scientifiques de niveau recherche, publiés ou non, émanant des établissements d'enseignement et de recherche français ou étrangers, des laboratoires publics ou privés. 


\title{
SBAS Guidelines for Shipborne Receiver based on IMO Res. A.1046 (27): EGNOS performance assessment in Norwegian coast
}

\author{
Sergio Magdaleno, Elisabet Lacarra, Nuria Blanco, ESSP \\ Manuel López, GSA \\ Email: Sergio.Magdaleno@essp-sas.eu, Elisabet.Lacarra@essp-sas.eu, Nuria.Blanco@essp-sas.eu, \\ Manuel.LopezMartinez@gsa.europa.eu
}

\section{BIOGRAPHIES}

Sergio Magdaleno holds a Ph.D. in Physics from the Complutense University of Madrid (Spain). After a 4 years research period in the National Institute for Aerospace Technology, where he was involved in the modelling of the ionosphere and the analysis of its impact on satellite communications, he joined to GMV in October 2011. There, he worked in EGNOS v2 subsystem as responsible of evolutions of the ionospheric module algorithms and in the EGNOS next version (EGNOS v3) as experimentation coordinator, ionospheric experimentation responsible and subsystem performance assessment responsible. In June 2015 he joined to the ESSP where he is the responsible of multimodal dynamics data campaign and is supporting the use of SBAS in the maritime domain, being the book captain of the "Guidelines for Manufacturers for the Implementation of SBAS in Shipborne Receivers". He has a strong background in ionosphere, GNSS signal propagation, EGNOS algorithms, SBAS system requirements and receiver standards.

Elisabet Lacarra received her master degree in Telecommunication Engineering in 2005. Later she was collaborating in different projects related to GNSS systems in GMV. Since 2009 she has been working inside the ESSP, firstly as performance expert for the analysis and assessment of EGNOS performance and later as EDAS Service expert for the management of all activities related to the EGNOS Data Access Service provision. Finally, she is leading the Receiver Standardisation and Evolution team, responsible of a laboratory that assesses the EGNOS performances in different types of receivers.

Nuria Blanco-Delgado holds a $\mathrm{PhD}$ in on Electrical and Computer Engineering from Instituto Superior Técnico, Lisbon, Portugal. She started her carrier as RadioNavigation Engineer at ESA/ESTEC in 2005; she worked then as Researcher at Instituto Superior Técnico and as GNSS Expert at CTAE. Since 2014 she works as Receiver Standardisation Expert at ESSP SAS where she is charge of a laboratory of certified and general purpose receivers, she participates on receiver standardisation bodies for the aviation (including UAS) and maritime domains, and she is also working on the development of guidelines for maritime and Open Service SBAS receivers.

Manuel Lopez-Martinez is Technology Officer in the European GNSS Agency (GSA), where he is supporting and fostering the adoption of Galileo and EGNOS in maritime, inland waterways and search and rescue applications. He received his PhD in System Engineering and Automation from the University of Seville in 2005. He got a permanent position as associate professor at the University of Seville in 2008, where he was teaching until he joined the GSA in 2013 as seconded national expert in the Market Development Department.

\begin{abstract}
One of the steps needed for the development of this new EGNOS maritime service is the definition of a minimum set of recommendations for receiver manufacturers to provide them with a clear view on how to design their SBAS receivers to be compliant with the requirements defined for such a service. EC, GSA, ESA and ESSP SAS have been working together since 2016 to develop guidelines for manufacturers for the implementation of SBAS in shipborne receiver. These guidelines, together with a set of test specifications, were developed in the frame of the SBAS Working Group created in the Special Committee (SC) 104 on Differential Global Navigation Satellite Systems (DGNSS) of Radio Technical Commission for Maritime Services (RTCM). The aim of these guidelines is to define the minimum SBAS messages needed to be processed by a SBAS receiver for the maritime sector to be compliant with the International Maritime Organization (IMO) Resolution A.1046.
\end{abstract}

This paper firstly presents the set of SBAS message type recommended by these SBAS guidelines as well as the preliminary list of tests that must be fulfilled to be compliant.

Secondly, GSA and ESSP, with the collaboration of The Norwegian Coastal Administration and Hurtigruten 
Cruises, have carried out a GNSS data collection campaign of 10 days along the Norwegian coast with the aim of assessing EGNOS performance at user level in the maritime domain at high latitudes in Europe.

Finally, the performances obtained with the receiver will be compared with the requirements of the IMO Res. A.1046 (27) to assess the feasibility of EGNOS for some maritime applications.

\section{INTRODUCTION}

EGNOS is the Satellite Based Augmentation System (SBAS) over Europe, currently designed to augment the GPS navigation system constellations by broadcasting additional signals from geostationary (GEO) satellites. Apart from providing positioning and timing service over Europe, EGNOS provides Integrity for Safety of Life applications. Some events of the GNSS system may lead to positioning errors that are greater than the ones allowed in certain safety critical applications. EGNOS provides Integrity by detecting and removing those system errors, and by alerting the user in due time when such errors occur and cannot be discarded.

EGNOS is also used in a wide range of applications (such as agriculture and surveying) that benefits the enhanced position solution with respect to GPS standalone solution. Moreover, EGNOS is widely used in aviation over Europe, which is a safety critical application. In July 2018, 180 airports have at least one EGNOS based procedure for landing and/or taking off.

In the maritime sector, there are several commercial receivers that are SBAS compatible according to their specification. However, there are no standards to support the use of the SBAS system in maritime receivers. In the scope of the maritime regulatory framework, the International Maritime Organisation (IMO) published the IMO resolution A.1046 (27) [RD-2], which establishes the requirements that a certain radionavigation system shall fulfil to be recognized by IMO as a component of the Worldwide Radionavigation Systems. This means that the system is recognized to be able to provide adequate position information within its service area and that the carriage of receiving equipment for use with the system satisfies the relevant requirements of the 1974 SOLAS Convention. In addition, the International Maritime Organisation (IMO) developed a number of performance standards covering other GNSS algorithms than SBAS, such as GPS [RD-5] and DGPS [RD-6]. Accordingly the International Electrotechnical Commission (IEC) produced several test specifications to accompany these IMO performance standards, which are covered in the IEC 61108 [RD-9], named "Maritime navigation and radiocommunication equipment and systems - Global navigation satellite systems (GNSS)". For example IEC 61108-1 refers to GPS and IEC 61108-4 to DGPS/DGLONASS. Although IEC 61108-4 allows the use of SBAS, there is no guidance for its implementation.
EGNOS meets the accuracy and availability requirements for general maritime navigation established in the IMO resolution A.1046 (27) [RD-2] and EGNOS provides integrity, which can be suitable for safety critical applications in the maritime sector. Because of that, EC (EGNOS owner), GSA (EGNOS program manager), ESA (EGNOS design agency) and ESSP (EGNOS service provider) are working in close collaboration to support the standardisation of SBAS in maritime receivers.

Firstly, a guidelines document for manufacturers for the development of SBAS receivers for the maritime domain ([RD-1]) has been presented and discussed at RTCM. These guidelines, together with a set of test specifications, were developed in the frame of the SBAS Working Group created in the Special Committee (SC) 104 on Differential Global Navigation Satellite Systems (DGNSS) of Radio Technical Commission for Maritime Services (RTCM). This document presents recommendations on the set of SBAS messages to be processed by an SBAS receiver for the maritime sector to be compliant with the International Maritime Organization (IMO) Resolution A.1046 (27) [RD-2]. The way messages should be processed as well as the system alerts applicable to comply with the requirements in [RD-2] are also explained. It also includes the tests specifications to be passed. A summary of these guidelines will be presented in this paper.

Secondly, GSA and ESSP, with the collaboration of The Norwegian Coastal Administration and Hurtigruten Cruises, have carried out a GNSS data collection campaign of 10 days and 9 nights along the Norwegian coast with the aim of assessing EGNOS performance at user level in the maritime domain at high latitudes in Europe. SBAS performance results of this data campaign will be presented to show the added value of EGNOS in maritime applications. A SBAS compatible receiver and a Software Receiver (both compliant with the developed SBAS guidelines) will be used to analyse the performance results in terms of accuracy and availability.

Finally, the performances obtained with the receiver will be compared with the requirements of the IMO Resolution A.1046 (27) [RD-2] to demonstrate the feasibility of EGNOS for some maritime applications. This resolution is particularly important as it states the minimum operational requirements that the maritime community requires from any navigation system in order to be accepted.

The work presented in this paper, which gathers the SBAS guidelines document and the SBAS performance results obtained in this Norway data campaign, are intended to support the integration of SBAS in the standardization process for maritime navigation and radiocommunication equipment and systems (IEC 61108, [RD-9]). 


\section{SBAS GUIDELINES}

EGNOS is the Satellite Based Augmentation System (SBAS) over Europe. EGNOS enhances the GPS navigation solution by broadcasting additional signals from geostationary (GEO) satellites. As shown in Figure 1, the architecture consists of a set of reference monitoring stations (at very well-known position) to receive GNSS constellation signals that will be processed in data processing centres to obtain some estimations of these errors that are also applicable to the users (i.e. ionospheric errors, satellite position/clock errors, etc.). Once these estimations have been computed, they are transmitted in the form of "differential corrections" by means of at least two SBAS Geostationary satellites, which covers Europe.

In consequence, vessels can receive these SBAS corrections from SBAS GEO satellites and apply them in order to obtain an enhanced navigation position with respect to GPS standalone. In addition, vessels could get advantage of the Integrity provided by SBAS, which warn users when there is an alert or issue in the system that could impact the positioning error.

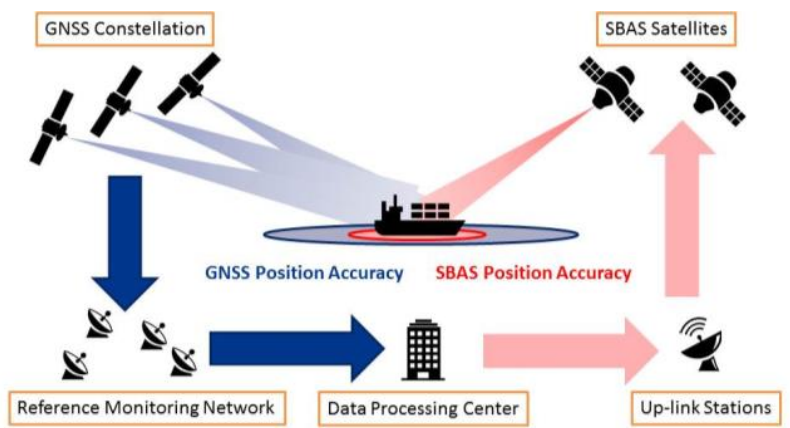

Figure 1 - EGNOS architecture

EGNOS corrections are composed of a number of different Message Types (MT). The format and detailed information on the content and their use for SBAS certified receivers for aviation are given in ICAO SARPs [RD-3] and RTCA SBAS MOPS [RD-4].

Among those SBAS messages, the SBAS guidelines [RD1] document proposes the use of the following Message Types to fulfil IMO Res A.1046()27 [RD-2] performance requirements using the SBAS SiS corrections and integrity data:

- Decode and apply fast corrections information broadcast through Message Types 2 to $\mathbf{5}$ and $\mathbf{2 4}$ corresponding to satellites selected by Message Type 1.

- Decode and apply long-term satellite error corrections broadcast though Message Types 24 and 25.

- Decode and apply ionospheric corrections if available broadcast through Message Type 26 for ionospheric grid points defined by Message Type 18.

- Apply tropospheric error corrections.

- Consider major warnings broadcast by the SBAS system:
- Satellite alerts in Message Types 2 to 6 and 24 ,

○ Ionospheric alerts in Message Type 26.

- Use the augmentation satellite ranging function if available broadcast through Message Type 9.

Additionally, an SBAS receiver should also process the following information in order to be compliant with IMO Res A.1046 (27) [RD-2] performance requirements:

- Information on the availability of the IMO Resolution A.1046 (27) [RD-2] compliant service broadcast by the system through Message Type 0.

- Time-out intervals for the validity of the messages as defined below. Message Type 7 contains information for computing the timeout interval for fast corrections.

- Almanac data from SBAS satellites broadcast through Message Type 17.

Once all corrections have been considered, the equipment shall compute its three-dimensional position, velocity and time (PVT) using a linearized, weighted least-squares solution as defined in [RD-1] and [RD-4].

Moreover, the SBAS guidelines [RD-1] also includes the tests that SBAS maritime receiver manufacturers can perform to verify that the receiver is complaint with the requirements at system level, with the Signal-In-Space RF characteristics and with the SBAS messages processing indicated in that document [RD-1].

For detailed information on the added value of the specific messages recommended, on the particularities of the way SBAS messages shall be processed and its interrelations, please refer to the SBAS Guidelines document [RD-1].

\section{DATA CAMPAIGN}

\subsection{Description}

In order to assess the EGNOS performance at user level in the maritime domain at high latitudes in Europe, a data campaign was carried out along the Norwegian Coast. The characteristics of this data campaign are:

- Route: In the northbound, the vessel departed from Trondheim to Kirkenes. The southbound was from Kirkenes to Bergen.

- Dates:

○ Departure from Trondheim: 22/02/2018 (doy 53)

- Arrival to and departure from Kirkenes: 26/02/2018 (doy 57)

- Arrival to Bergen: 03/03/2018 (doy 62)

- Vessel: MS Finnmarken (more information in https://www.hurtigruten.co.uk/our-ships/msfinnmarken)

Figure 2 shows the route followed by the vessel along the mission.

International Technical Symposium on Navigation and Timing (ITSNT) 2018

13-16 Nov 2018

ENAC, Toulouse, France 


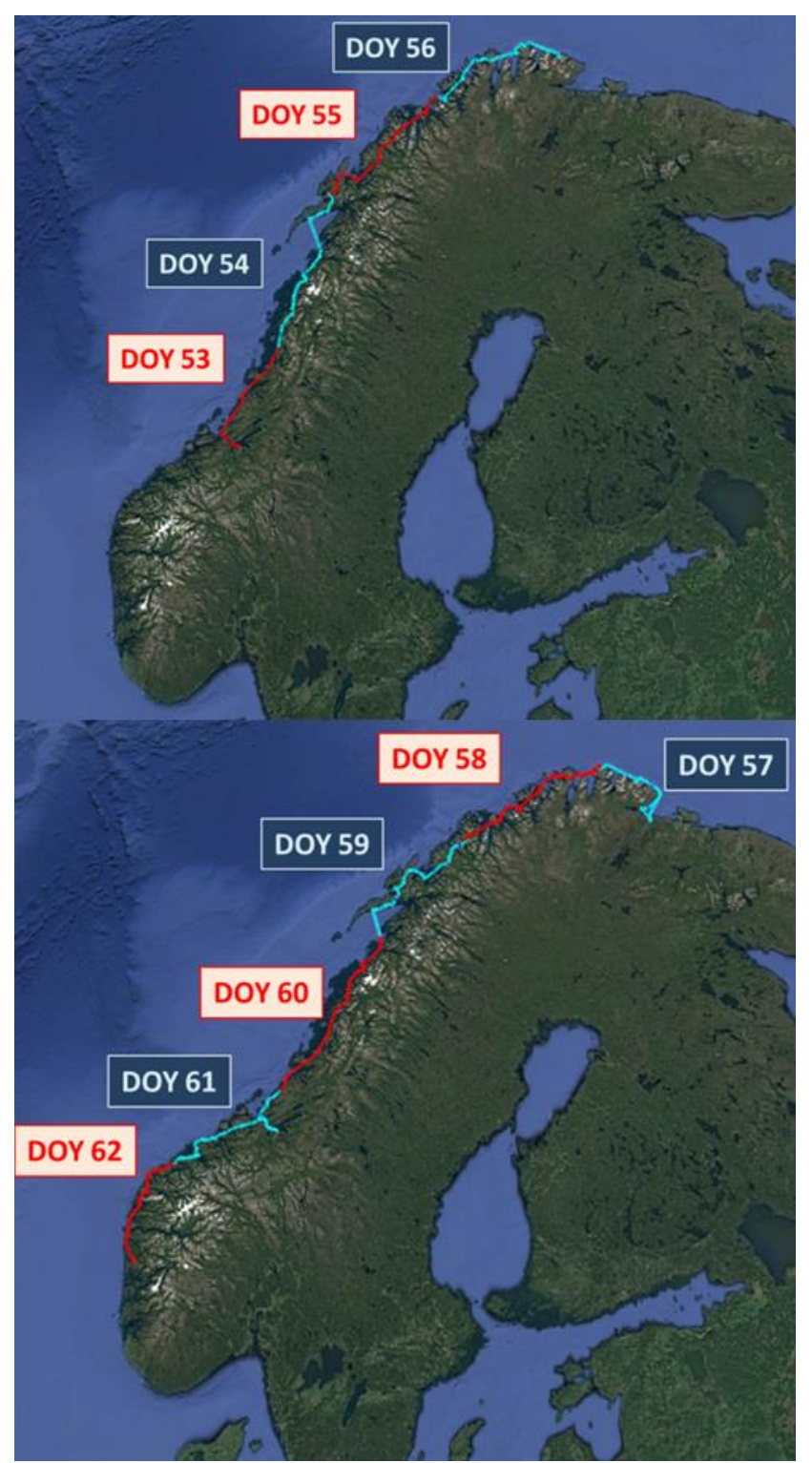

Figure 2 - Data collection geographical path

For the data collection, the following equipment was used:

- GNSS Dual-frequency Receiver with the following characteristics:

$$
\begin{array}{ll}
\circ & \text { GPS/GLONASS L1/L2 } \\
\circ & \text { SBAS }
\end{array}
$$

- GNSS Antenna.

- L1 RF Recorder (Labsat 3).

- Coaxial cable RG214 (25 m).

- Splitter 1 In SMA - 2 Out SMA.

The position of the GNSS antenna installed in the MS Finnmarken vessel is showed in Figure 3.

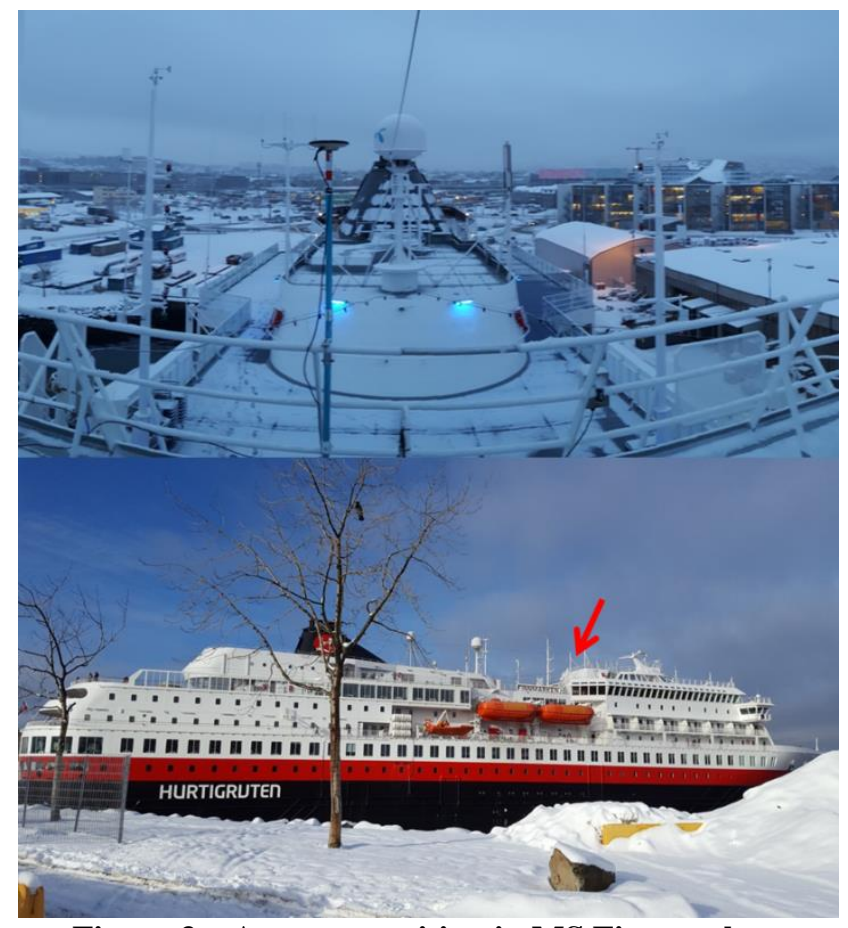

Figure 3 - Antenna position in MS Finnmarken

\subsection{Methodology}

The EGNOS receiver installed in the vessel directly reported the PVT solution based on EGNOS. Additionally, this receiver provided dual frequency observations which were injected offline to Precise Point Positioning (PPP) algorithms in order to compute the precise position of the vessel at any time. Besides, these dual frequency observations were also injected in the Software receiver, gLAB [RD-8], to compute the EGNOS performance in line with the Guidelines for Manufacturers for the Implementation of SBAS in Shipborne Receivers ([RD-1]). It is noted that gLAB was developed following the SBAS guidelines and that it passed the test specification provided in those guidelines [RD-1]. A schema of the followed process is showed in Figure 4.

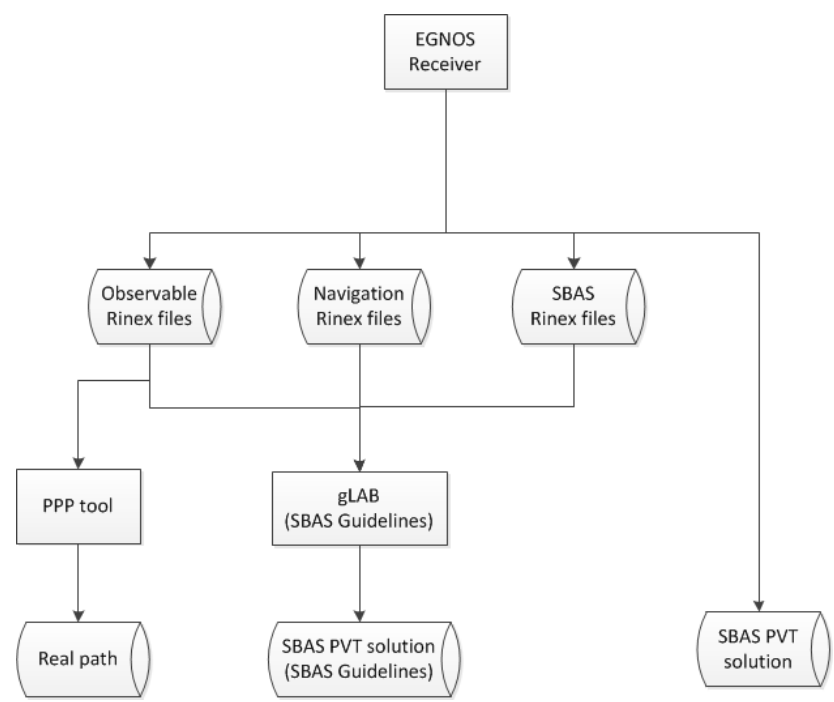

Figure 4 - Data process scheme 
Finally, the L1 RF data recorded by Labsat 3 was injected in a GPS standalone receiver to obtain the GPS standalone PVT solution. The aim of that was to provide a comparison between GPS and EGNOS performance in that region.

\subsection{Performance results}

In this section the comparison between the PVT solutions obtained using the data sets indicated in the previous section are provided.

Firstly, the EGNOS signal availability is checked. This performance is computed using system data by the EGNOS Service Provider. The EGNOS monitoring information shows that the EGNOS signal in space (SIS) availability was $100 \%$ during the data campaign period.

The strength of the EGNOS signal along the route is also checked. Figure 5 shows the temporal evolution of the carrier-to-noise ratio (C/N0) values for the three EGNOS GEO satellites. During the data collection, PRN 120 and 123 were operational, whereas PRN 136 was set in test mode. The analysis depicts that PRN 123 and PRN 136 signal were received with a high strength. PRN 120 was received with lower $\mathrm{C} / \mathrm{N} 0$ especially during the days that the vessel was in the North of Norway (doy from 55 to 59), because it was observed from low elevations, i.e. in the border of the PRN 120 coverage area.

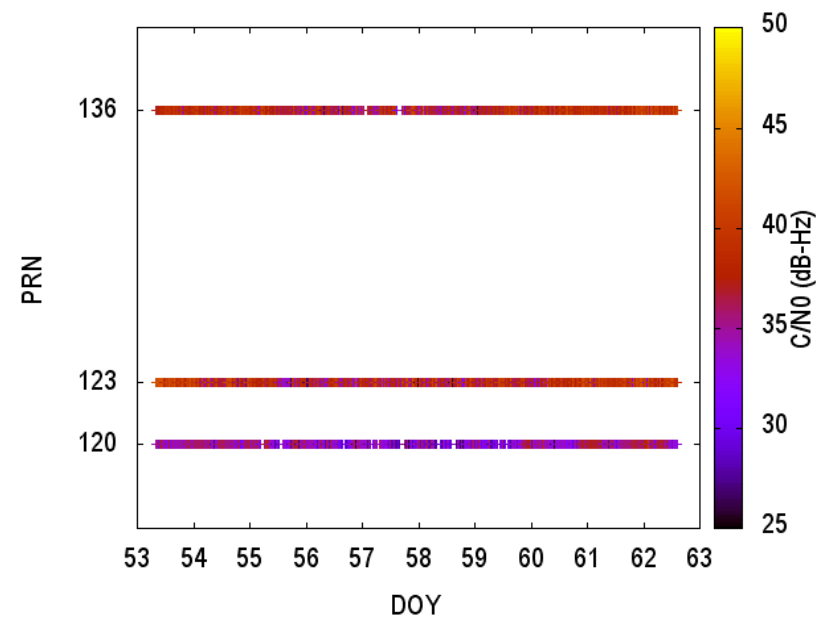

Figure 5 - Strength of all EGNOS GEO signals.

Although the EGNOS SIS availability was $100 \%$, some data gaps were detected, that is, lack of EGNOS signal tracking by the receiver, linked to the orography of the region, not to the EGNOS system. The EGNOS user support website (https://egnos-user-support.esspsas.eu/new_egnos_ops/resources-tools/egnos-visibilitymaps) shows the areas over Europe where there is no visibility of one or both EGNOS operational geostationary satellites (PRN 120 and PRN 123 by the time of the data campaign). In Figure 6 an example of this EGNOS Geostationary satellites visibility map is presented, covering longitudes from 13 to 20 degrees East and latitudes from 67 to 69 degrees North. As it can be seen, there are some areas close to mountains or fiords in which a GEO satellite could not be observed.

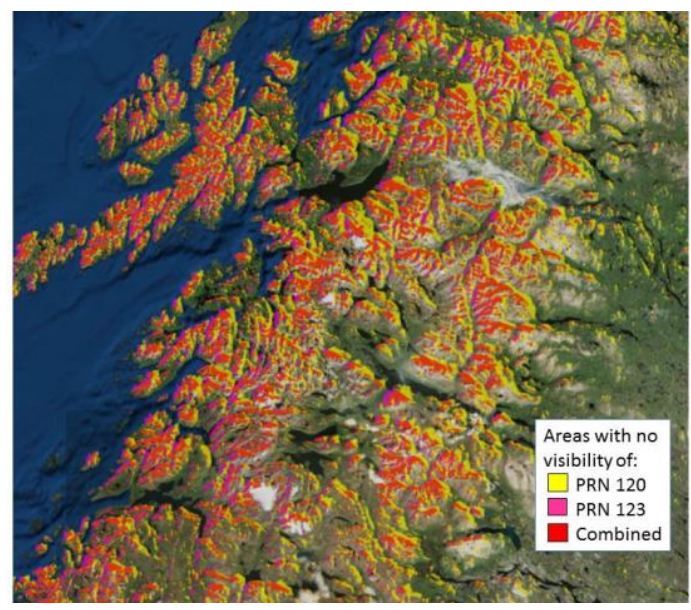

Figure 6 - EGNOS GEO satellites visibility map

It is noted that the coverage area of GEO satellite PRN 120 was very limited in the Northeast European Area (see Figure 7), which impacted the reception of EGNOS messages from RN120 when the vessel was located in the Northeast area, positions in which the elevation angle was very low. From $23^{\text {rd }}$ August, PRN 136 was introduced in EGNOS operational platform replacing PRN 120. PRN 120 was in test mode during the period of the data campaign. Considering the EGNOS messages of this satellite, the availability of EGNOS SIS messages is improved from $98.89 \%$ to $99.34 \%$. Thus, the current EGNOS operation platform improves the EGNOS SIS availability over the Northeast of Europe.

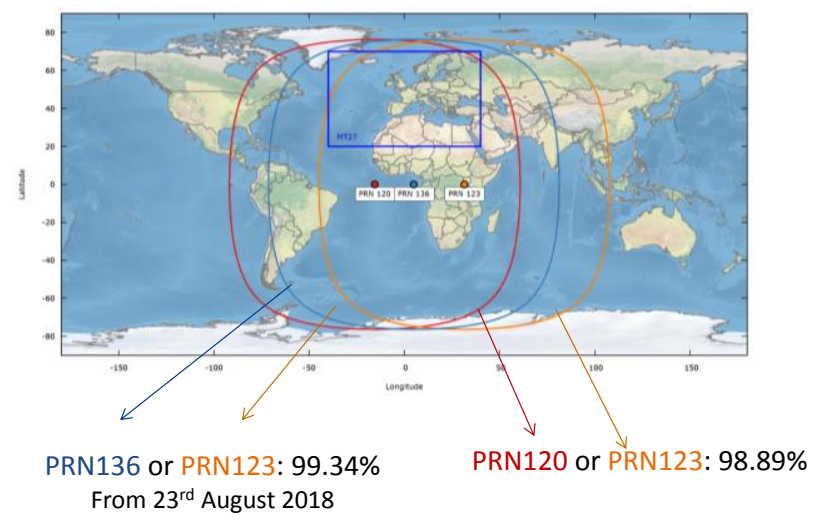

Figure 7 - EGNOS GEO satellites coverage area

The impact of the orography in the availability of the EGNOS signal received by the receiver is greater according to the elevation angle of the SBAS Geo satellite. Figure 8 and Figure 9 depicts the EGNOS signal availability in the EGNOS receiver as function of the latitude. This figure confirms that the impact of the orography is greater according the latitude is increasing (or the SBAS Geo satellite elevation angle decreased). 


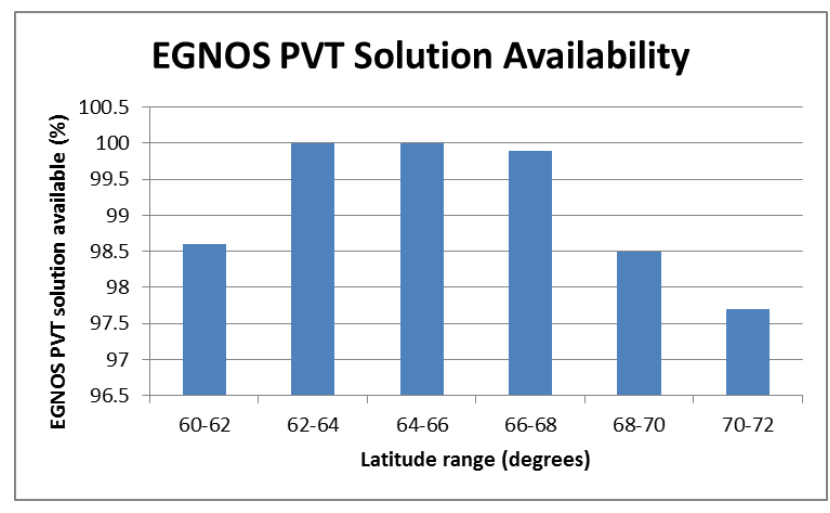

Figure 8 - EGNOS position availability in function of latitude obtained from EGNOS Rx.

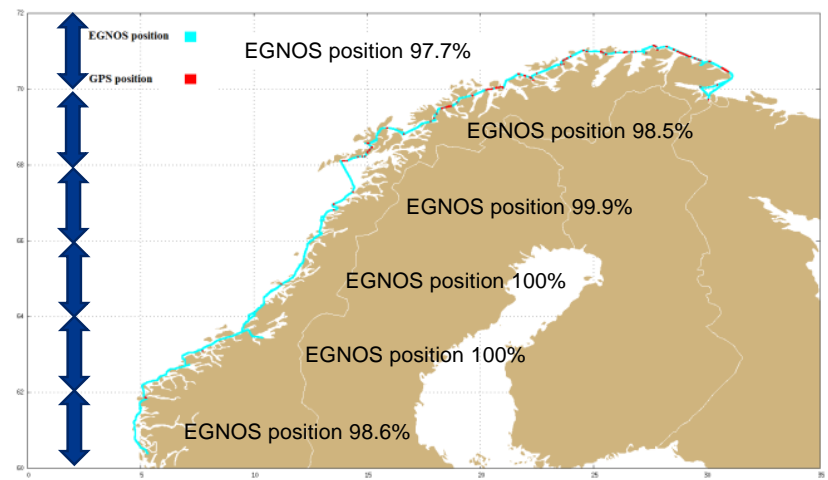

Figure 9 - EGNOS position availability in function of latitude obtained from EGNOS Rx over a map.

Figure 9 shows that the EGNOS position availability is nominally $99.9 \%$ from 60 to 68 degrees latitude. In the latitudes from 60 to 62 degrees the EGNOS position is only $98.6 \%$ because the vessel is located a port located very close to a mountain that obstructs the GEO satellite visibility, as it is seen in Figure 10.

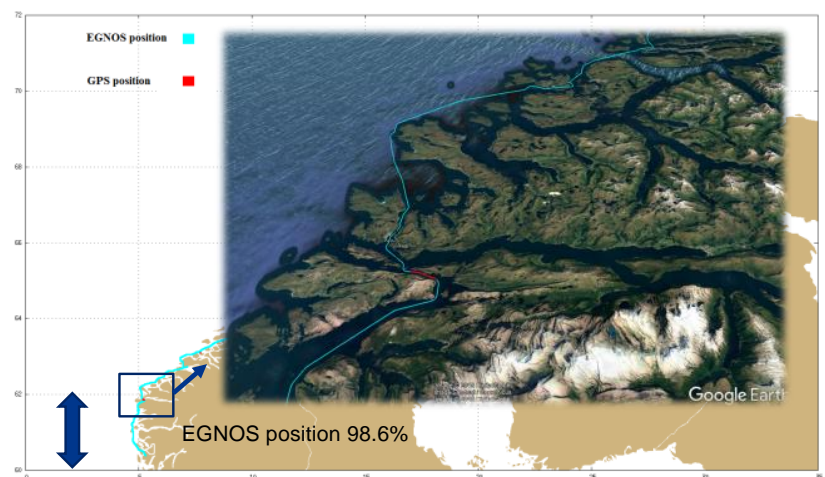

Figure 10 - EGNOS position availability in function of latitude obtained from EGNOS Rx over a map.

Finally the accuracy of the computed solution is evaluated. The Horizontal Navigation Solution Error (HNSE) is defined as the 2D radial error of the GNSS estimated position (PVT solution provided by the receiver) with respect to the actual position (Position solution provided by PPP algorithms) of the vessel. The HNSE histogram is computed for the EGNOS receiver (blue), the EGNOS software receiver (coral) and the GPS standalone receiver (purple) and presented in Figure 11.

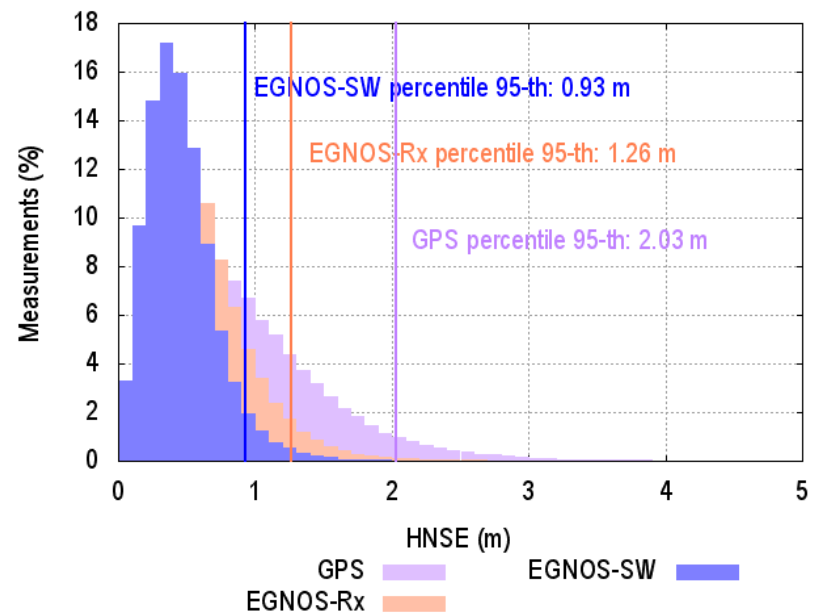

Figure 11 - HNSE histogram and 95-th percentile values.

This figure shows that EGNOS software receiver (gLAB) presents the lowest horizontal navigations system errors and a HNSE 95-th percentile of $0.93 \mathrm{~m}$, which are better than the ones provided by GPS standalone solution. The EGNOS receiver also presents enhanced position solution with respect to GPS and a $95 \%$ percentile of $1.26 \mathrm{~m}$. Finally, the GPS standalone receiver presents the worst accuracy values and, consequently, the greatest HNSE 95th percentile with a $2.03 \mathrm{~m}$ value. As expected, these results confirm that EGNOS provides better accuracy performance than GPS standalone receiver.

Figure 12 shows the daily HNSE 95-th percentile values obtained for the EGNOS receiver (purple line), gLAB EGNOS software receiver - (green line) and GPS standalone receiver (blue line).

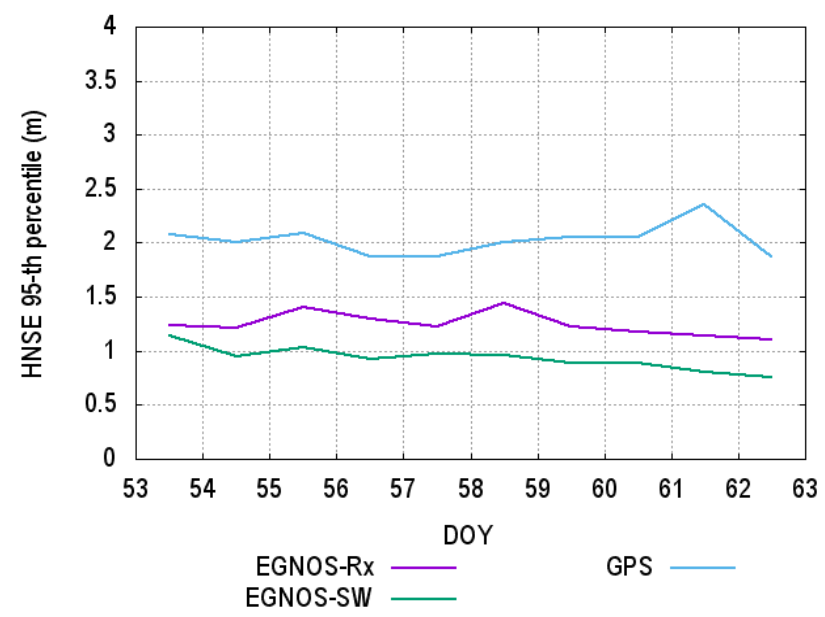

Figure 12 - HNSE 95-th percentile values obtained using EGNOS and using GPS standalone.

The daily HNSE 95-th percentile values showed above confirm that EGNOS software receiver (gLAB) provides the best (the lowest HNSE values) accuracy performances with values about $1 \mathrm{~m}$. It is remarked that this software receiver is aligned with the SBAS guidelines [RD-1]. It is also observed that the EGNOS receiver provides a very good HNSE 95-th percentile values, about $1.2 \mathrm{~m}$, slightly greater than those obtained from EGNOS SW receiver.

International Technical Symposium on Navigation and Timing (ITSNT) 2018

13-16 Nov 2018

ENAC, Toulouse, France 
Considering that gLAB is a Software tool in postprocessing, it does not have time processing restrictions like the real-time receiver. In addition, other algorithms considerations (such as smoothing filter using phase, kalman filter, least squares applicability, dynamic conditions configuration, EGNOS message type processing ...) could provide slightly different position results. As expected, the GPS standalone receiver provides the worst HNSE 95-th percentile values, almost always greater than $2 \mathrm{~m}$. These values show that the receiver that used EGNOS provides a more accurate position during the whole period evaluated that the receiver GPS standalone.

Table 1 shows the relationship between the number of satellites used to compute the PVT solution and the HNSE 95-th percentile for the EGNOS Receiver (orange columns), gLAB - EGNOS software receiver - (blue columns) and GPS standalone receiver (purple columns). The average of used satellites in EGNOS is around 1-2 satellites lower with respect to GPS during the days (doy 55 - 59) that the vessel is located in the North part of Norway, whereas the navigations position errors are considerably better using EGNOS navigation solution with respect to GPS.

Table 1. Average of the number of satellites used for PVT and HNSE 95-th percentile per day.

\begin{tabular}{|c|c|c|c|c|c|c|}
\hline \multirow{2}{*}{ DOY } & \multicolumn{2}{|c|}{ EGNOS Rx } & \multicolumn{2}{c|}{ EGNOS SW } & \multicolumn{2}{c|}{ GPS } \\
\cline { 2 - 7 } & $\begin{array}{c}\text { HNSE } \\
(\mathrm{m})\end{array}$ & $\begin{array}{c}\text { Used SV } \\
\text { Average }\end{array}$ & $\begin{array}{c}\text { HNSE } \\
(\mathrm{m})\end{array}$ & $\begin{array}{c}\text { Used SV } \\
\text { Average }\end{array}$ & $\begin{array}{c}\text { HNSE } \\
(\mathrm{m})\end{array}$ & $\begin{array}{c}\text { Used SV } \\
\text { Average }\end{array}$ \\
\hline 53 & 1.24 & 9.4 & $\mathbf{1 . 1 4}$ & 9.1 & $\mathbf{2 . 0 8}$ & 9.4 \\
\hline 54 & 1.21 & 9.0 & $\mathbf{0 . 9 5}$ & 9.0 & $\mathbf{2 . 0 0}$ & 9.7 \\
\hline 55 & 1.41 & 8.1 & 1.03 & 8.2 & $\mathbf{2 . 0 9}$ & 9.8 \\
\hline 56 & 1.30 & 7.6 & $\mathbf{0 . 9 2}$ & 8.0 & 1.87 & 9.8 \\
\hline 57 & 1.23 & 7.8 & $\mathbf{0 . 9 7}$ & 8.0 & 1.87 & 9.9 \\
\hline 58 & 1.44 & 7.8 & $\mathbf{0 . 9 6}$ & 8.0 & $\mathbf{2 . 0 0}$ & 9.8 \\
\hline 59 & 1.23 & 8.6 & $\mathbf{0 . 8 9}$ & 8.5 & $\mathbf{2 . 0 5}$ & 9.7 \\
\hline 60 & 1.18 & 9.2 & $\mathbf{0 . 8 9}$ & 9.1 & $\mathbf{2 . 0 5}$ & 9.6 \\
\hline 61 & $\mathbf{1 . 1 4}$ & 9.3 & $\mathbf{0 . 8 0}$ & 9.1 & $\mathbf{2 . 3 6}$ & 9.5 \\
\hline 62 & $\mathbf{1 . 1 1}$ & 9.8 & $\mathbf{0 . 7 6}$ & 9.5 & 1.87 & 9.4 \\
\hline
\end{tabular}

\section{CONCLUSIONS}

A summary of the document providing guidelines to receiver manufacturers for the development of SBAS receivers in compliance with the International Maritime Organization (IMO) Resolution A.1046 (27) [RD-2] have been presented. A software receiver has been developed that implements the proposal in [RD-1] to confirm that the expected performance requirements are satisfied.

- The EGNOS monitoring information shows that the EGNOS signal in space availability was $100 \%$ during the data campaign period. But it should be noted that some data gaps were detected, that is, lack of EGNOS signal tracking by the receiver, linked to the orography of the region, not to the EGNOS system.

- As expected, it is also demonstrated that EGNOS provides better accuracy performance than GPS

International Technical Symposium on Navigation and Timing (ITSNT) 2018

13-16 Nov 2018

ENAC, Toulouse, France
Standalone, including outside the EGNOS Service Area defined in Message Type 27. Accuracy figures are degraded between $30 \%$ and $50 \%$ in GPS standalone.

- Additionally to this better accuracy performance, EGNOS provides integrity as added value to the PVT solution with regards to the use of GPS Standalone. That added value (integrity) allows the use of EGNOS for some operation that GPS Standalone cannot be used.

\section{ACKNOWLEDGMENTS}

ESSP and GSA would like to express their gratitude to the Norwegian Coastal Administration for this great collaboration in order to test the EGNOS performances in the Norwegian coasts.

ESSP and GSA would like to thank Hurtigruten Cruises and MS Finnmarken for letting us use its cruise ship for this GNSS data campaign.

Finally, the authors would like to acknowledge the efforts done by EC and the GSA to continuously support the EGNOS programme.

\section{REFERENCES}

[RD-1] Draft Guidelines for Manufacturers for the Implementation of SBAS in Shipborne Receivers Including Methods of Testing and Required Test Results, 31 July 2017

[RD-2] IMO Resolution A.1046(27) Worldwide Radionavigation System, 20 Dec 2011.

[RD-3] ICAO Standards and Recommended Practices (SARPS) Annex10 Volume I (Radio Navigation Aids)

[RD-4] RTCA MOPS DO 229 Revision E [RD-5] IMO Resolution MSC.112(73),"Adoption of the revised performance standards for shipshore Global Positioning System(GPS) receiver equipment, December 2000

[RD-6] IMO Resolution MSC.114(73) DGPS and DGLONASS maritime radio beacon receiver equipment.

[RD-7] IMO Resolution MSC.401(95) performance standards for multi-system shipborne radionavigation receivers

$\begin{array}{ll}\text { [RD-8] } & \text { gLAB Software } \\ & \text { http://www.gage.upc.edu/gLAB }\end{array}$

[RD-9] IEC 61108 - Maritime navigation and radiocommunication equipment and systems - Global navigation satellite systems (GNSS) http://www.iec.ch

[RD-10] EGNOS user support website https://egnos-user-support.essp-sas.eu

[RD-11] Grant, A., Last, D., Kuncheva, L. 2003. Marine DGNSS Availability and Continuity. Journal of Navigation, 56, 353-369 